\title{
Gastroentero-histopathology Studies of Synthesized Naproxen Esters in Young Healthy Sprague-Dawley Rat Model
}

\author{
Mansura Akter ${ }^{1}$, Sajal Kumar Saha ${ }^{2}$ and S. M. Abdur Rahman ${ }^{2}$ \\ ${ }^{1}$ Department of Pharmacy, Faculty of Life \& Earth Science, Jagannath University, Dhaka, Bangladesh \\ ${ }^{2}$ Department of Clinical Pharmacy and Pharmacology, Faculty of Pharmacy, University of Dhaka, Dhaka, \\ Bangladesh
}

Received: November 12, 2014; Accepted: March 11, 2015; Published (web): March 29, 2015

\begin{abstract}
Naproxen and its synthesized esters namely naproxen methyl ester, $\mathrm{C}_{15} \mathrm{H}_{16} \mathrm{O}_{3}$ (compound 1), ethyl ester, $\mathrm{C}_{16} \mathrm{H}_{17} \mathrm{O}_{3}$ (compound 2) and isopropyl ester, $\mathrm{C}_{17} \mathrm{H}_{20} \mathrm{O}_{3}$ (compound 3) were subjected to NSAID induced gastro-ulcergenecity studies on young, healthy male rat model. Rats (Rattus novergicus: Sprague-Dawley strain) of 2-months old weighing 95-105 g were administered with naproxen (10 mg/kg b.w.) compound 1 (10.609 $\mathrm{mg} / \mathrm{kg}$ b.w.), compound 2 (11.217 mg/kg b.w.) and compound 3 (11.826 mg/kg b.w.) twice daily for 4.5 days. The naproxen esters appeared to induce significantly less GI injury and bleeding both in microscopic and macroscopic examinations. This study can be a basis of reference for further acute, chronic or subchronic toxicity studies in various in-vivo models.
\end{abstract}

Key words: Naproxen, esters, gastro-ulcergenecity, toxicities

\section{INTRODUCTION}

The gastrointestinal (GI) adverse effects of nonsteroidal anti-inflammatory drugs (NSAIDs) occur more frequently in the elderly patients taking antiplatelet/anti-coagulants and those with co-morbidities such as rheumatoid arthritis, obesity, heart failure and hypertension. ${ }^{1-3}$

One of the central mechanisms by which NSAIDs induce GI injury and bleeding is by disruption of the tissue surface barrier to gastric acid and other luminal cytotoxic agents. ${ }^{4-6}$ Surface hydrophobic barrier can be rapidly attenuated by NSAIDs through chemical interaction and other damaging agents and/or conditions. ${ }^{7,8}$ Leukocyte adherence to the vascular endothelium is a critical early event in pathogenesis of NSAID-gastropathy, and also plays an important role in the development

Correspondence to: S. M. Abdur Rahman Tel: +88029661920-73, cell: +8801732477343

E-mail: rahman_du@yahoo.com

Dhaka Univ. J. Pharm. Sci. 14(1): 49-53, 2015 (June) of NSAID-induced injury in the small intestine. Therefore, to improve analgesic/anti-inflammatory activity with minimum side effects, increase COX 1 /COX 2 selectivity or to enhance lipophilicity numerous NSAID derivatives have been prepared and were reported to have better bioavailability, less irritation to the gastric mucosa and anti-oxidant capacity. ${ }^{11-15}$ We synthesized three ester derivatives of naproxen for example methyl, ethyl and isopropyl ester (1-3) by direct esterification reaction and the derivatives were screened for the gastrointestinal toxicity tests in young healthy rat model.

\section{MATERIALS AND METHODS}

Naproxen, carboxymethyl cellulose, sodium (0.25\%) were collected from ACI pharmaceuticals Ltd., ketamine $\mathrm{HCl}$, USP (50 mg/ml) and $0.9 \%$ normal saline from Gonoshasthaya Pharmaceuticals Ltd., Bangladesh. NSAID induced gastroenteropathy in young, healthy rat model was studied following standard methods ${ }^{11,12}$ to see overall effect on the 
health of the animals, in connection to gain in body weight over the 4.5 days treatment schedule. The sub chronic model allows one to assess the NSAID's GI toxicity, with regard to both GI bleeding (faecal haemoglobin, haematocrit reduction), the development of intestinal perforation and adhesions. $^{12}$ Young healthy male rats (Rattus novergicus: Sprague-Dawley strain) of 2-months old weighing 95 - 105 g were randomly divided<smiles>COc1ccc2cc([C@@H](C)C(=O)O)ccc2c1</smiles>

S- Naproxen [S-(6-Methoxy naphthyl propionic acid)]<smiles>CCCC(=O)[C@H](C)c1ccc2cc(OC)ccc2c1</smiles>

Naproxen ethyl ester (compound 2)

Dose selection and route of administration. The doses of naproxen employed in the rat studies were between $106.67 \mathrm{ppm}$ in the diet, which was equivalent to $10 \mathrm{mg} / \mathrm{kg}$ body weight. Using a fivefold scaling factor dose of compound 110.609 $\mathrm{mg} / \mathrm{kg}$ b.w., compound $211.217 \mathrm{mg} / \mathrm{kg}$ b.w. and compound $311.826 \mathrm{mg} / \mathrm{kg}$ b.w. were selected and administered. These doses were comparable with a single naproxen dosing in humans of approximately $225 \mathrm{mg}$ which would correspond to 1 standard dose of $225 \mathrm{mg} /$ day and test samples were orally administered twice daily for 4.5 days. ${ }^{12}$

Numbering of scores. Ulcer scoring was done as $0=$ no ulcer/normal colored stomach, $0.5=$ red coloration, $1.0=$ superficial spot, $1.5=$ hemorrhagic streak, 2 = deep ulcer, 3.0 = perforation following methods reported by Vogel et al. ${ }^{16}$ Ulcer index was measured using the following formula:

$$
\mathrm{UI}=\mathrm{U}_{\mathrm{N}}+\mathrm{U}_{\mathrm{S}}+\mathrm{U}_{\mathrm{P}} \mathrm{X} 10^{-1}
$$

Where, UI = Ulcer Index, $\mathrm{U}_{\mathrm{N}}=$ average number of ulcers per animal, $U_{S}=$ average number of severity into five groups (6 rats/group) which were administered orally with $0.1 \mathrm{ml} / 10 \mathrm{~g}$ bw of $0.25 \%$ $\mathrm{w} / \mathrm{v}$ carboxy methyl cellulose (CMC) suspended saline (control group), naproxen (reference group) and the test compounds 1-3 (test groups) at equimolar dose of $10 \mathrm{mg} / \mathrm{kg}$ b.w. twice daily for 4.5 days. The entire sample was prepared and vortexed in $0.25 \%$ w/v CMC suspended normal saline.<smiles>COc1ccc2cc([C@@H](C)C(Cl)OC)ccc2c1</smiles>

Naproxen methyl ester (compound 1)<smiles>COc1ccc2cc([C@@H](C)C(O)OC(C)C)ccc2c1</smiles>

Naproxen isopropyl ester (compound 3)

score, $\mathrm{U}_{\mathrm{P}}=$ ulcer probability (\% incidence) for each group.

Intestinal adhesions were assessed by a scale of 0 to 4 . The small intestines were removed as a mass and were gently pulled apart for assessment of sticking and scored as follows: $0=$ normal; $1=$ slight sticking, pull apart without tearing; $2=$ sticking, must cut adhesions to pull apart; $3=$ numerous adhesions, difficulty in cutting intestines apart; 4 = massive adhesions, cannot be cut apart. Intestinal perforations were counted after filling the distal half of the small intestine with $5 \mathrm{ml}$ of water and counting the number of breaks where leaks occurred.

Assessment of gastro intestinal side effects. The rats were anesthetized with ketamine and sacrificed after 3 hours of administration of the compounds. After abdominal dissection, the stomachs were slightly taken out and $10 \%$ formalin solution was injected into the stomach. The distended stomach was immediately tied to the pyloric sphincter using another surgical suture to avoid 
leakage of the formalin solution. Finally, the stomachs were removed, immersed in the same solution to fix the outer layer of the stomach and then dissected along the greater curvature, rinsed with tap water to remove the gastric contents (e.g. food fragments, blood clots) and examined under a dissecting microscope $(20 \times 6.3)$ to assess the formation of ulcers. The sum of the length $(\mathrm{mm})$ of all lesions for each stomach was used as the ulcer index.

Assessment of hematology. Blood samples drawn from descending aorta were centrifuged for 10 minutes at $3000 \mathrm{rpm}$ to separate serum for biochemical analysis. The samples were stored at $20{ }^{\circ} \mathrm{C}$ for further use. Biochemical parameters ${ }^{11}$ like total blood cell count (nutrophil infiltration, platelet, WBC, RBC), haematocrit (index of anaemia caused by gastro intestinal bleeding), hemoglobin $(\mathrm{Hb})$ (index of NSAID-induced GI bleeding), bleeding time, clotting time were determined by Abott's Cell -DYN-3200 SL auto analyzer using kits manufactured by Roche Diagnostic Division in City Hospital, Dhaka, Bangladesh.

Histopathological studies. The gastric and intestinal (distal half) specimens obtained from the control and treated groups of animals were fixed in $10 \%$ buffered formalin for 24 hours and embedded in paraffin. Section of 5-6 $\mu \mathrm{m}$ were cut and stained with haematoxylin-eosin for photomicroscope observations (Nikon, Japan). ${ }^{11,12}$

Statistical analysis. The statistical analysis was done by using one-way ANOVA followed by Dunnett's test. $\quad \mathrm{P}<0.05$ was considered as significance.

\section{RESULTS AND DISCUSSION}

In this study, we have evaluated the GI side effects of three synthesized aliphatic esters; naproxen methyl ester (compound 1), ethyl ester (compound 2) and isopropyl ester (compound 3) using young healthy rat model after multiple doses of the test NSAID, based upon several indices of GI bleeding (intestinal and faecal haemoglobin, and haematocrit determination as an estimate of the development of anemia), as well as the macroscopic appearance of intestinal perforations and adhesions in the subchronic model. This approach was based upon the studies reported by Lichtenberger et al. ${ }^{8}$ with naproxen-soy lecithin ester and Blackler et al. ${ }^{12-14}$ with various rat models.

Table 1. Hematologic parameters obtained from blood collected from descending aorta after oral administration of equimolar $10 \mathrm{mg} / \mathrm{kg}$ b.w. twice daily for 4.5 days.

\begin{tabular}{lccccccc}
\hline Group & $\begin{array}{c}\mathrm{Hb} \\
\mathrm{g} / \mathrm{dl}\end{array}$ & $\begin{array}{c}\text { Nutrophil } \\
\%\end{array}$ & $\begin{array}{c}\text { Platelet } \\
10^{9} / \mathrm{l}\end{array}$ & HCT & $\begin{array}{c}\text { Clotting } \\
\text { time }\end{array}$ & $\begin{array}{c}\text { RBC } \\
10^{12} / \mathrm{l}\end{array}$ & $\begin{array}{c}\text { Bleeding } \\
\text { time }(\mathrm{min})\end{array}$ \\
\hline Control & $10.25 \pm 0.34$ & $20.25 \pm 3.42$ & $541.25 \pm 36.88$ & $35.6 \pm 1.192$ & $3.9 \pm 0.15$ & 5.80 & 41.25 \\
$\mathrm{~N}$ & $9.35 \pm 0.22$ & $26.25 \pm 3.57$ & $490 \pm 48.48$ & $33.73 \pm 0.76$ & $3.9 \pm 0.15$ & 5.31 & 33.75 \\
$\mathrm{P}$ value & 0.0721 & 0.2706 & 0.4324 & 0.2823 & 1 & 0.988 & 0.586 \\
$\mathrm{MN}$ & $10.29 \pm 0.67$ & $18.5 \pm 1.32$ & $382.5 \pm 57.54$ & $35.43 \pm 2.48$ & $3.9 \pm 0.15$ & 5.78 & 33.75 \\
$\mathrm{P}$ value & 0.54 & 0.9648 & 0.650 & 0.0592 & 0.9513 & 0.995 & 0.497 \\
EN & $9.92 \pm 0.28$ & $23 \pm 3.51$ & $420 \pm 45.46$ & $35.75 \pm 1.27$ & $4.04 \pm 0.04$ & 5.78 & 37.5 \\
$\mathrm{P}$ value & 0.479 & 0.595 & 0.0837 & 0.698 & 0.419 & 0.875 & 0.543 \\
IN & 10.732 & $20.5 \pm 1.26$ & $413.75 \pm 72.04$ & $37.27 \pm 0.99$ & $4.08 \pm 0.04$ & 6.16 & 37.5 \\
P value & 0.337 & 0.947 & 0.1662 & 0.322 & 0.316 & 0.659 & 0.649 \\
\hline
\end{tabular}

In hematologic assessment, there was no sign of any statistically significant changes in hematologic parameters although mean bleeding time increases in case of esters than naproxen, which were statistically found to be insignificant considering all biological variations (Table 1). Mean platelet and neutrophil count were decreased in case of esters compared to naproxen and least in case compound 1 (382.5 \pm $\left.57.54 \times 10^{9} / \mathrm{l}\right)$. Mean HCT measurements were increased in case of all naproxen esters compared to parent drug which are also found to be insignificant and therefore, no hematologic indication of GI side effects. 
$P$ values considered significant at $(P>0.05)$. Histopathological studies resulted in very little detectable damage in the stomach or small intestine equivalent to naproxen (Figure 1). Macroscopically, there was a small amount of bleeding found in compound 1 treated group $(\mathrm{n}=2$ ) (scoring $0.5 \pm 0.5$ for stomach; $0.35 \pm 0.5$ for intestine) and compound
2 treated group $(\mathrm{n}=1$ ) (scoring $0.625 \pm 0.5$ for stomach; $0.31 \pm 0.5$ for intestine). However, microscopically, no significant sign of ulceration or perforation were found in histo-pathologic findings of stomach and intestine in either group of control or treated animals (Figure 2).

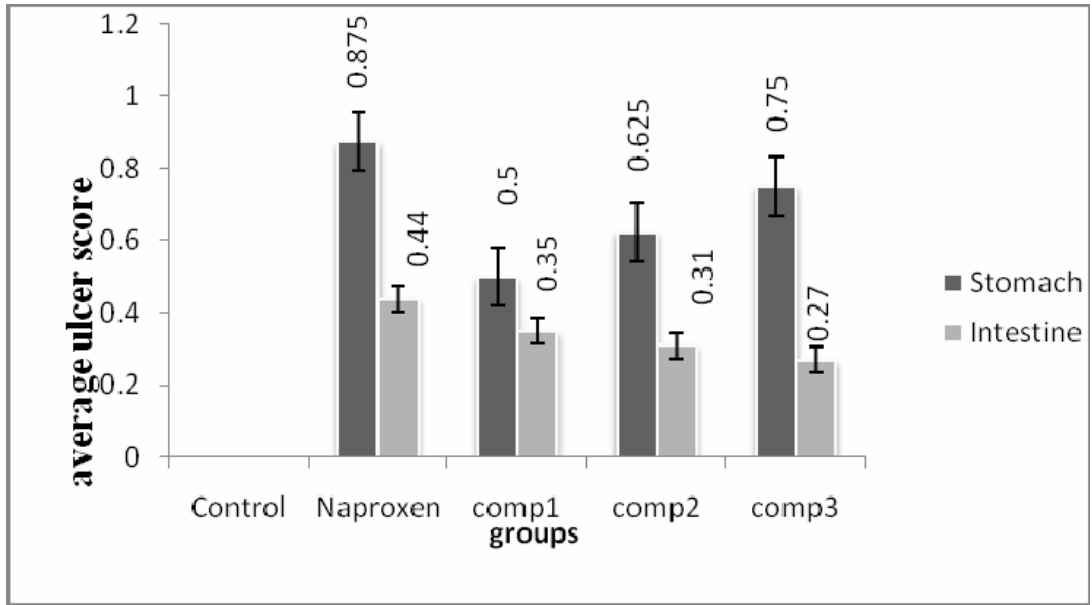

Figure 1. Gastric ulcerogenic effects of naproxen vs synthesized compounds in stomach and distal half of intestine after $10 \mathrm{mg} / \mathrm{kg} \mathrm{bid} 4.5$ days dosing period in young healthy rat model.

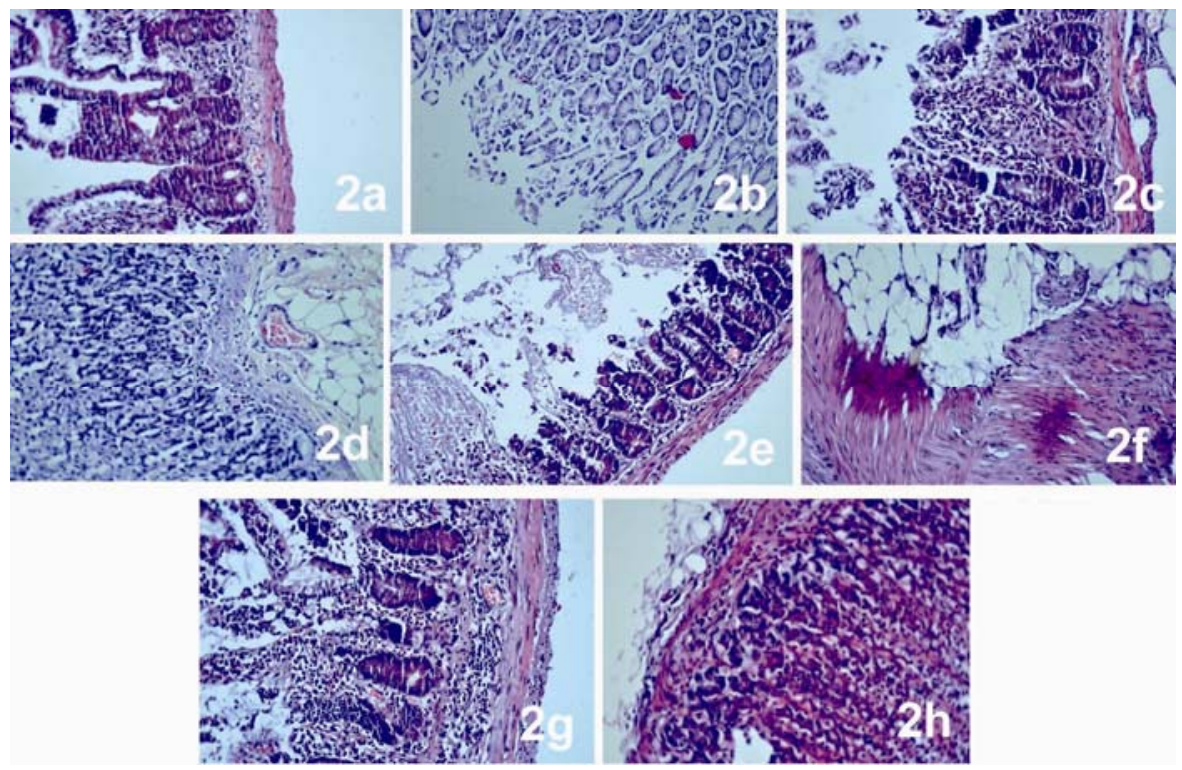

Figure 2. Evaluation of the GI toxicity of synthesized esters of naproxen (1-3) in comparison to an equivalent dose of naproxen (10 mg/kg, bid for 4.5 days) in healthy young rat model. Naproxen treated (2a, 2b), methyl ester treated (2c, 2d), ethyl ester treated (2e, 2f), and isopropyl ester treated intestine and stomach $(2 \mathrm{~g}, 2 \mathrm{~h})$.

Further extensive studies are needed to predict absorption pattern in terms of compartmental modeling and bioavailability of the esters.
Considering all the above data, it can be said that at an equimolar dose of naproxen $10 \mathrm{mg} / \mathrm{kg}$ body weight neither of the naproxen derivatives showed 
significant changes in young healthy rat model except negligible scoring damage and bleeding. Further studies may be done to a larger extent to reveal the real picture of the derivatives at various doses.

\section{ACKNOWLEDGEMENTS}

The authors wish to acknowledge the supports of Jahangirnagar University, Bangladesh and City Hospital, Dhaka Bangladesh for providing laboratory facilities to carry out the experiments.

\section{REFERENCES}

1. Solomon, D.H. and Gurwitz, J.H. 1997. Toxicity of nonsteroidal anti-inflammatory drugs in the elderly: is advanced age as risk factor? Am. J. Med. 102, 208-215.

2. Hernández-Díaz, S. and Rodríguez, L.A. 2002. Incidence of serious gastrointestinal bleeding/perforation in the general population: review of epidemiologic studies. J. Clin. Epidemiol. 55, 157-163.

3. Aro, P., Storskrubb, T., Ronkainen, J., Bolling-Sternevald, E. Engstrand, L., Vieth, M., Stolte M., Nicholas, J., Talley, J. and Agre'us, L. 2006. Peptic ulcer disease in a general adult population: the Kalixanda study: a random populationbased study. Am. J. Epidemiol. 163, 1025-1134.

4. Goddard, P.J., Hills, B.A. and Lichtenberger, L.M. 1987. Does aspirin damage canine gastric mucosa by reducing its surface hydrophobicity? Am. J. Physiol. 252, 421-430.

5. Goddard, P.J., Kao, Y.C. and Lichtenberger, L.M. 1990. Luminal surface hydrophobicity of canine gastric mucosa is dependent on a surface mucous gel. Gastroenterology 98, 361-370.

6. Hills, B.A., Butler, B.D. and Lichtenberger, L.M. 1983. Gastric mucosal barrier: hydrophobic lining to the lumen of the stomach. Am. J. Physiol. 244, 561-568.

7. Giraud, M.N., Motta, C., Romero, J.J., Bommelaer, G. and Lichtenberger, L.M. 1999. Interaction of indomethacin and naproxen with gastric surface-active phospholipids: a possible mechanism for the gastric toxicity of nonsteroidal anti-inflammatory drugs (NSAIDs). Biochem. Pharmacol. 57, 247-254.
8. Lichtenberger, L.M., Zhou, Y., Dial, E.J. and Raphael, R.M. 2006. NSAID injury to the gastrointestinal tract: evidence that NSAIDs interact with phospholipids to weaken the hydrophobic surface barrier and induce the formation of unstable pores in membranes. J. Pharm. Pharmacol. 58, 1421-1428.

9. Wallace, J.L., Keenan, C.M. and Granger, D.N. 1990. Gastric ulceration induced by nonsteroidal antiinflammatory drugs is a neutrophil-dependent process. Am.J. Physiol. 259, 462-467.

10. Wallace, J.L. and McKnight, G.W. 1993. Characterization of a simple animal model for nonsteroidal antiinflammatory drug induced antral ulcer. Can. J. Physiol. Pharmacol. 71, 447-452.

11. Blackler, R., Syer, S., Bolla, M., Ongini, E. and Wallace, J.L. 2012. Gastrointestinal-sparing effects of novel NSAIDs in rats with compromised mucosal defence. PLoS ONE. 7, e35196.

12. Lichtenberger, L.M., Romero, J.J., De Ruijter, W.M., Behbod, F., Darling, R., Ashraf, A.Q. and Sanduja, S.K. 2001. Phosphotidylcholine association increases the antiinflammatory and analgesic activity of ibuprofen in acute and chronic rodent models of joint inflammation: relationship to alterations in bioavailability and cyclooxygenase- inhibitory potency. J. Pharmacol. Exp. Ther. 298, 279-287.

13. Wallace, J.L., Caliendo, G., Santagada, V. and Cirino, G. 2010. Markedly reduced toxicity of a hydrogen sulphidereleasing derivative of naproxen (ATB-346). Bri. J. Pharmacol. 159, 1236-1246.

14. Nalini, C.N., Ramachandran, S., Kavitha, K. and Saraswathi, V.S. 2011. Glycolamide esters of naproxen as potential prodrugs - synthesis, spectral studies and preliminary pharmacological screening. IJRPBS. 2, 11121117.

15. Uludag, M.O., Caliskaun, B. and Alkan, D. 2011. Stable ester and amide conjugates of some NSAIDs as analgesic and anti-inflammatory compounds with improved biological activity. Turk. J. Chem. 35, 427-439.

16. Vogel, W.H., Scholkens, B.A., Sandow, J., Muller, G. and Vogel, W.F. 2002. Drug discovery and evaluation, $2^{\text {nd }} E d n$. Springer, NewYork, ISBN-13: 978-3540423966. pp. 670725. 